\title{
Stay home and be unfair: The amplification of inequalities among families with young children during COVID-19
}

\section{Marco Pitzalis | Emanuela Spanò}

Department of Social and Political Sciences, University of Cagliari, Cagliari, Italy

\section{Correspondence}

Marco Pitzalis, Department of Social and Political Sciences, University of Cagliari, Via Sant'Ignazio da Laconi, 78, 09123 Cagliari CA, Italy.

Email: pitzalis@unica.it

\begin{abstract}
This article focuses on the educational practices and strategies mobilised by Italian families with children aged six years and younger, during the health crisis caused by the COVID-19 pandemic in Italy, in 2020. Specifically, we analyse practices and strategies mobilised by families from different social milieus living in rural or urban contexts. We argue that the shift in childcare practices and needs during the pandemic promoted the reaffirmation of traditional gender stereotypes and patterns of gendered labour division through the blurring of temporal and spatial boundaries between paid work, domestic labour and childcare. Our findings shed light on how differences in household circumstances, such as the availability of space in the home, have impacted disparities in childcare. Specifically, how different housing conditions have profoundly influenced the coping mechanisms of both children and parents during school closures. We conclude by discussing teachers' attempts to realise educational activities for supporting continuity in the pedagogical relationship, in a context of different family conditions and educational patterns.
\end{abstract}




\section{1 | INTRODUCTION}

How children are brought up has undergone a profound transformation in the last 30 years. Some sociologists note that the rhetoric of lifelong learning is related to the project of a totally pedagogised society (Ball, 2009; Bernstein, 2000; Robertson \& Sorensen, 2018; Singh, 2015). Accordingly, informal and formal training and educational activities have been extended to occupy a larger space in children's lives and families' strategies. All the activities related to sport, leisure and culture have been integrated in a process of progressive institutionalisation. These activities are always realised in private spaces, under adult control and a professional eye in formal organisations or associations. In this sense, the family has come, more and more, to externalise and privatise educational work and childcare.

On the one hand, the division of educational work (between families and other educational actors) has been contentious. The question over who will have primacy in the child's education and is better equipped to protect them, recognise their needs and defend their rights and safety, is conflictual. These conflicts involve the relationship between the family and school. On the other hand, social class can explain differences in educational strategies chosen by families and associated understandings of the purpose and function of education (Lareau, 2003).

In Italy, the COVID-19 epidemic caused a shock to the healthcare system, as in other countries. The associated societal rupture and moral panic (Cohen, 1972) led to the closing, on 4 March 2020, of public and private kindergartens and preschools until the start of the new school year in September 2021-with important regional disparities. ${ }^{1}$ In our hypothesis, this rupture may have reinforced the ongoing processes of privatisation and domestication of childhood (James et al., 2002; Satta, 2012). On the other hand, it has created a discontinuity in educational and pedagogical practices by reasserting old and new forms of inequality related to family socioeconomic background, cultural capital and individual abilities (Santagati \& Barabanti, 2020). The question on which we focus in this article is if, how and to what extent these disparities have affected the reconfiguration of spaces (Knoblauch \& Löw, 2017) and the re-organisation of time-allocation and practices in child-rearing, and the relationships to school and learning as mediated by digital devices.

The starting point for our analysis is the assumption that during 2020-2021, schools as organisations and their actors (i.e., teachers, students, parents and principals) have experienced a rupture of the normal school experience. This rupture represents a potential paradigm shift (Kuhn, 1970) that has brought an extreme and tangible actuality of long-lasting innovation and change processes to different spheres of school life: educational and organisational autonomy, technology and its legitimate uses, legitimate pedagogical paradigms, school-family relationships, professional teaching culture, student autonomy, family roles and choices in the shaping of the school experience, and the role and function of school management. In sum, what is usually represented by policymakers and policy analysts as a unitary education system is in reality an ensemble of those various segments and units where the tangible school experience may be very specific. The micro dimension is indeed pertinent to understanding the process of change produced by reforms and innovation.

We do not consider the COVID-19 crisis an exceptional and transitory element which will leave no traces on the school and its forms. Instead, we see crisis as a constitutive element of education systems and an extraordinary accelerator of ongoing change. For this reason, it represents a base from where to freshly observe social reality.

Starting from these premises and taking into account the perspective of new childhood sociology (Corsaro, 2017), we propose a conflictual approach to the family and its relationships with other families and the institutions with which they interact (Bourdieu, 1994; Lareau, 2000, 2003). We want to focus, especially, on increased inequalities caused by school closures for 0-6 year-old children and their families in terms of gender as well as spatial and social strategies mobilised during the pandemic. We claim, in fact, that during crises when the links between school institutions and children and, more generally, between public spaces and education are weakened, the mechanisms of social reproduction act more strongly and inequalities are both amplified and reshaped.

More specifically, this article focuses on the educational practices and strategies mobilised by families, with children in the ages 0-6 years, from different social milieus and living in rural or urban contexts, during the health 
crisis. The central question is how social actors have mobilised their specific resources (social, cultural and economic) in response to the challenges of their new lives.

The article is built around three intertwined axes: gender, space and social class. First, we argue that the pandemic shift opened the possibility that long-standing patterns of gender relations would be reaffirmed through the blurring of temporal and spatial boundaries between paid work, domestic labour and childcare. Second, we propose an insight on the spatial dimension of childcare-connected disparities, showing how different housing conditions have profoundly influenced the coping mechanisms of both children and parents during school closures. We conclude by discussing teachers' attempts to realise educational activities for supporting continuity in the pedagogical relationship, in a context of different family conditions and educational patterns. Teaching practices are analysed in relationship to the diversity in family circumstances that teachers have to deal with.

\section{2 | METHODS}

The analysis presented in this article draws on the results from in-depth interviews collected during qualitative research realised in three different Italian areas not uniformly hit by the COVID-19 crisis: Milan, Sardinia (urban and rural areas) and Naples (central and peripheral neighbourhoods). In the first phase of the pandemic Milan was one of the cities most affected by COVID-19, reaching the highest numbers of infections in the whole country. In contrast, Sardinia (especially the rural areas) and Naples were initially affected by the virus to a lesser extent.

The research began in March 2020 and is still ongoing. The data comprises 80 online interviews. Between March and June 2020, 40 in-depth interviews were conducted with parents from different social and economic backgrounds (25), and with teachers (15) from various private and public kindergartens and primary schools located in Milan, Naples, Cagliari and other towns and villages in Sardinia. More specifically, parents were free to choose whether to be interviewed alone or as a couple; we interviewed 15 single parents-ten mothers and five fathers-and ten couples.

Between September and November 2020, over 40 in-depth interviews were conducted with primary and preprimary schoolteachers located in rural (15), suburban (15) and urban areas (15) of Sardinia. In the second phase, the interviews were collected by selecting groups of teachers working at the same school. By this, we sought to document different points of view on school strategies activated to cope with distance learning in relation to the diversity of family backgrounds.

All of the online interviews have been conducted and recorded through the platforms Teams, Skype and Google Meet with an average duration of an hour. From a methodological point of view, the analysis of the interviews sought to identify emerging themes with a grounded theory approach (Glaser \& Strauss, 1967).

\section{3 | A GENDERED PERSPECTIVE ON THE ORGANISATION OF THE WORK REQUIRED FOR EDUCATION AT HOME}

The COVID-19 pandemic in Italy saw hundreds of thousands of people switch to working from home, significantly blurring the temporal and spatial boundaries between paid work, domestic labour and childcare. This dramatic shift opened the possibility for a reaffirmation of traditional gendered labour divisions in families due to the restrictive measures introduced during the pandemic.

This section examines whether and how this happened, especially in relation to childcare tasks. In the interviews conducted, the theme of the circumstances for mothers confined to home and committed to full-time domestic activities, emerged as one of the most recurrent and emotionally dense themes, unveiling in this way what England has referred to as a stalled revolution (England, 2010) of the gendered division of childcare-related 
labour. We consider two dimensions of this labour: the first is connected to school assignments; the other to the sphere of leisure and play.

In general, this unprecedented situation acted as an external shock on families. Distance education for children, working from home for parents, limited or no availability of any external aid to the nuclear family (grandparents, maids and babysitters) were all factors that put the household organisation and balance between paid and unpaid work under stress, possibly forcing families to renegotiate previous arrangements.

More specifically, two main patterns related to the gendered division of educational work emerged. The first entails working and low-middle-class families that reproduce a traditional division of labour with the man as breadwinner and a gendered reciprocal typisation (Kaufman, 1995) of educational tasks. The second pattern arises among middle- and upper-class families with the highest-educated women and egalitarian gender roles and practices. In those family configurations, the rupture caused by the COVID-19 pandemic has paradoxically pushed women to regain an intensive role in child-rearing.

Referring to the first pattern, among unemployed women with lower levels of education or sharing traditional gender role patterns, the amount of time spent on childcare was comparatively higher already before the pandemic. The following excerpt from an interview with a Sardinian couple-in which the man was a skilled worker and the woman a public office trainee-shows a conflictual negotiation about the sharing of domestic roles and the duties connected with child-rearing. When asked about this sharing, the couple expressed an uneasiness in revealing to the interviewer an unequal division of domestic labour. Hence, they felt obliged to justify it to an external eye, in this way revealing the inextricable connection between conflict and complicity in the reciprocal negotiation of gender roles (Bourdieu, 1998). This negotiation seems to find a resolution through specialisation, or more accurately, a reciprocal typisation (Kaufman, 1995) of parental roles: mother's role connected to supporting school (work sphere), while the father's role was connected to game and ludic activities (leisure sphere). It is a division which uncovers persistent gender roles and habits:

Mother: Darling, there's nothing to be ashamed of.

Father: No, it's because you said 'I'm the only one to take care of children!'

Mother: No, I didn't say that only I take care of them, but mostly me.

Father: Now you! But when we both worked...

Mother: Okay, anyway I think you've hit a sore spot... Mainly I take care of the child, but when my husband stops working, we divide the tasks. For example, in this period in quarantine, I helped G. to do his homework. I also tried to keep him busy as much as possible by making him do activities with tempera or pastels, etc.

Father: I take care of keeping them busy with games. I try to make them play!

(online interview, mother and father of a 4-year-old son, Dolianova, April 2020)

Among middle-class families, with college-educated men and women both doing their jobs from home, the negotiation of tasks connected to child-rearing seemed to exclude conflicts and the fear of social judgement. In the case of one mother, a middle-class primary teacher from Cagliari, in a kind of economy of gratitude (Hochschild, 2013), she said that she tried to protect her husband-a public employee-from the second job of childcaring:

[I take care of the baby at home] but let's say that my husband sometimes does it [...] since he works at home, he works eight hours [a day], now he's working from home like me. So, let's say that even when he isn't working, I tend to say 'No, you rest, I'll take care of the children', so let's say that I spend most of the time with them, that's it.

(online interview, mother of a daughter aged two and a one-year-old son, Cagliari, May 2020)

In the Italian context, the variables typically affecting the gendered division of domestic labour seem to be constant in time and space by age, education, urban contexts, children's age, gender role attitudes, partnerships, employment relations (ISTAT, 2011). The woman's disadvantage is stable. Yet not all women are equally 
overburdened. Middle- and upper-class women with the highest levels of education, or those sharing egalitarian gender patterns and practices in the couple, reported a significantly higher share of domestic work and childcare than their partners (Naldini, 2015).

For this reason and with reference to the second pattern that emerged from the interviews, what seems relevant is that with the pandemic, the newly emerging work arrangements, like working from home, have deepened unequal patterns in the division of childcare labour, even among women who are perceived to be privileged. The next account was recounted by a highly educated woman in a dual-earner couple, the owner of an accounting firm in Milan, who has found herself completely alone in the management of their two-year-old child after the closure of the nursery and her partner's disengagement:

All to be redone! I had to keep the baby at home because it was just me! My partner was physically present because he worked from home like me, but he is completely on another planet because he is a programmer and therefore not much has changed for him. So, he was at home but it's as if he wasn't there. I don't blame him though. It went like this-the little girl, the house and all the additional work fell back on me, really heavy! They tried at the nursery to continue doing activities but it was difficult, even compared to my investment: buy the paints, the brushes, assemble, create and she didn't even like these activities! So, if you do it in a school equipped with 20 other children getting dirty in the face it makes sense. Do it between me and her, I try a couple of times but it's hard. I can't get her interested.

(online interview, mother of a two-year-old daughter, Milan, March 2020)

In another account, a mother employed in a big communications agency in Milan emphasised, on the one hand, her guilt for having no time to dedicate to her children's education. On the other, she experienced a sense of abandonment and fatigue in the attempt to balance home chores and childcare.

We both continued to work a lot. I have experienced a sense of abandonment as a family and as a working woman because for those who have not been able to stop working, manage children at home without being able to dedicate time to them, with online homework, etc. My partner was at home but it was like he wasn't there. I was desperate! Cook, wash, work, take care of them, of the dog [...] Some days I had to leave my little son for many hours alone in front of the tablet to play because I could not be with him, I could not offer him an alternative and so this was unfair, I got frustrated. In addition, I felt a very strong sense of tiredness, so when I sometimes finished my shift, I collapsed, slept and I was not a present, creative parent, I was a tired parent.

(online interview, mother of a 5-year-old son, Milan, June 2020)

In sum, families found themselves suddenly obliged to renegotiate previous arrangements. Sometimes, arrangements during the pandemic have just confirmed old forms of gender inequality, while in other cases, have provoked an unexpected re-traditionalization of gender roles in childcaring. While low- and middle-class women seem to accept this renegotiation of gender roles with greater adaptability in order to face crises and school closure, upper-class women seem to be caught between feeling guilt for their difficulty in dealing with their child's education and the wish for a more reasonable share in domestic labour.

\section{4 | DISADVANTAGED HOMES AND THE REDISCOVERY OF OUTDOOR SPACES}

The processes of privatisation and domestication of childhood (James et al., 2002; Satta, 2012) currently characterise the life of Western children and have progressively substituted free play in open spaces with supervised and 
overprotected play within the walls of homes, schools and recreation centres (Satta, 2010). During the first phase of the lockdown and school closures these ongoing processes have been amplified and have revealed the centrality of space and housing conditions in reproducing unequal childhoods (Lareau, 2003).

In this section, we focus on the spatial dimension of disparities in childcare and show how different housing conditions have profoundly influenced the ways in which children and parents have coped with school closures. We identify three different aspects connected to spatial inequalities and consequently strategies used by families. The first is represented by inadequate space at home; for example, lack of rooms for individual use or other facilities. The second aspect is related to the availability of open space and its consequences for the possibility of free movement and outdoor activities. The third aspect is about the valorisation of common spaces-such as communal gardens and courtyards-previously abandoned in terms of collective uses.

The dimension of indoor spaces-small dwellings, poor natural lighting, low acoustic comfort, day rooms characterised by inadequate privacy during the increasing number of telephone and video connectionshave significantly impacted childcare and education practices. ${ }^{2}$ In an interview conducted in a Neapolitan peripheral neighbourhood, for example, the absence of privacy caused by the sharing of small spaces has strongly conditioned the possibility of combining distance education for children and working from home for parents:

There is no longer a dividing line, there is a total admixture of private life, understood precisely as a work activity, as well as physical spaces. I work in a company that allowed me to work from home immediately but we have a tiny apartment, so I'm in this living room and kitchen, [my daughter] has her own bedroom but is still here. You work; however, if she comes to me, I keep her, then she wants to play, then the dad comes, then maybe the dad takes a shower and I keep her. This also influenced distance learning. We didn't stay in contact very much, first of all, because I believe that at this age, distance learning doesn't work at all. But above all, because the house, the space did not allow it.

(online interview, mother of a 4-year-old daughter, Naples, May 2020)

The presence of balconies, terraces, gardens and even just the view from the windows also had a relevant weight in resisting physical confinement and organising a time for children (Ennew, 1994) no longer marked by the rhythms of face-to-face school. This is illustrated in the next excerpt from an online interview with a respondent in Milan: a mother reveals her choice of moving to her parents' big house with a garden-filled with objects of great beauty-in order to survive lockdown with a two-year-old child.

We survived just because I have the great fortune of having a grandfather with a garden and so we moved there for three months and that was the great luck [...] The house was even bigger than ours and full of many beautiful things-paintings, works of art, objects-because it is a house that hosted my grandparents who passed away, then my dad, but it is a house that looks like a museum, even when you go into a room with the child you lose a good half hour!

(online interview, mother of a two-year-old daughter, Milan, March 2020)

Those spatial inequalities have, for open spaces, been partly subverted by the relationship between rural and urban contexts. While the previous excerpt shows the strategy of a family with a high inherited economic and cultural capital, we observe that living in rural villages guarantees for many people an easy access to safe open spaces. In this way social inequities linked to confinement appear to be mitigated, as illustrated by the following account. It is the case of a mother from a small mountain village in Sardinia that highlights the opportunity for her child to spend time outdoors despite the absence of open spaces at home. 
My luck is that we live in a mountain village. I don't even live in the centre of the country and therefore I had the opportunity to go out on the street and be outdoors, take walks even during the first lockdown because here if you go outside, you meet no one [...] My son really needs to be outdoors because my house has no balcony or terrace.

(online interview, mother of a three-year-old son, Seui, May 2020)

The third theme is connected to the spatial dimension. Frequently emerging from the interviews was the return of condominium gardens or courtyards as spaces for children. With the above-mentioned process of domestication of childhood, the disappearance of children from those spaces and their relocation to the private and domestic space of upper floors had established the end of their uncontrolled play in the open air, of their spatial freedom, of their presence in the public space (Satta, 2010).

Paradoxically, home confinement has forcefully reaffirmed the importance of those spaces as places for children (Rasmussen, 2004) ${ }^{3}$ places free from adult direct control but protected from the external world by welldefined boundaries (e.g., railings and gates). Those boundaries have become more impassable because of a moral panic (Cohen, 1972), generated by the pandemic. In this interview, a father from Cagliari expressed the strategy of controlled freedom enacted by adults in the space of the courtyard. It also reveals how children can absorb fears from adults and make them their own.

My son has shifted from being together for many hours with companions to having to stay home. We simply told him that there was coronavirus outside the home and that if he went out, he could hurt us and that the police and the carabinieri were in control. In the building we have an internal courtyard and when we let them go out to play it happened that he looked out at the gate and hid as he saw the police go by [...] Fortunately we have at least that courtyard!

(online interview, father of a three-year-old son, Cagliari, March 2020)

Finally, different interviewees from urban contexts also recalled that through the space of the condominium garden, they found a social and participative solution for childcaring. The rediscovery of a sense of community in a moment of strong physical but also social isolation, in fact, helped this mother from a popular central neighbourhood of Naples, to reinvent spaces, time and relationships for child-rearing:

Thanks to a condominium space that is so large, we were able to recreate a small community of parents. Obviously, we took turns, only two adults staying with the children, always very careful. We used an entire area with a big garden, we planted tomatoes, we put in a slide, my husband built a swing [...] everything. We put in a swing for the older ones, a swing for the little ones with the supports and then we stayed down until six in the evening to let the children stay.

(online interview, mother of a three-year-old son and five-year-old daughter, Naples, May 2020)

To summarise, interviews show different family strategies related to a creative use of internal and external spaces with the goal of overcoming-through free play, bodily movement, 'safe' face-to-face relations with pairs within the constraints imposed by lockdown. We also observed that the need for open and green spaces, for sunlight and not crowded places, has also contributed to the re-figuration (Knoblauch \& Löw, 2017) of the relation between rural and urban context, close and open spaces, and individual and collective uses of common spaces.

\section{5 | RECREATING SCHOOLING}

In this section, we try to understand how teachers' attempts to realise educational activities, by establishing a continuity in the pedagogical relationship with children, have met different families' conditions and educational 
patterns. On the one side, teachers have been constrained to give a sense to their activities and role-inventing strategies to capture the attention of children in virtual spaces of communication where bodies were absent. Under normal conditions, most of the activities involve the manipulation of objects, physical contact and emotive sharing. On the other side, the success of these virtual activities depends on parents' collaboration.

Following Lareau (2003), we consider two models of parenting style linked to social class and cultural capital. In her view, middle-class parents tend to conform to a cultural logic of child-rearing based on concerted cultivation, centred on the enrolment of children in numerous age-specific organised activities. Instead, the strategies of working-class and poor parents emphasise the accomplishment of natural growth, characterised by few organised activities, more free time and deeper, richer ties within the extended families.

Among nurseries and kindergarten teachers, physical contact is the constitutive element of the intersubjective teacher-pupil relationship. This centrality exemplifies and explains the specific difficulties they encountered in reorganising distance learning. For this reason, teachers interviewed tried to be more creative and engaging in the activities proposed for children, adopting pedagogies based on manual skills, physical involvement and inventiveness that required a central role for parents in terms of time, ability and commitment.

Hence, some teachers did not feel comfortable assigning online activities out of concern for contributing to the amplification of inequalities among pupils and their families. Moreover, they have to rely on the collaboration of families to succeed. The following excerpt illustrates the concerns of teachers about their activities. It also contains an evaluation of families' contexts and reliability, as well as a stigmatisation of families who totally delegate the education of their children to school.

To be honest, I am a little reluctant to send things because of the 20 children we have, three or four of them are doing the activities. And my question is [...] 'Does the parent follow him?' This technology can be an incredible tool, the DAD or LED, as they call it in childhood: 'Educational links at a distance.' However, a big gap is created where there is already a gap in the concrete context [...] It is something that does not work when there is no alliance with the parents; some are actually used to seeing the school as a parking: I put my son there and when he goes out, he is well-educated by the school.

(online interview, primary teacher, Cagliari, April 2020)

Difficulties in engaging children are also related to a digital divide and children lacking effective electronic devices. In an intense account, a teacher from a kindergarten located in the popular Neapolitan neighbourhood of Quartieri Spagnoli recalls her challenging attempts to deal with the material and cultural deprivation of working-class and poor parents living in an underprivileged context. This meant, for example, opting for asynchronous activities that only required a mobile phone. The teacher highlights that the activities were successful, thanks to active parental involvement.

I have to deal with parents without devices or perhaps with children who had devices but did not have their parents next to them. Some couldn't even read my messages! [...] Every morning we sent an email to the parent to tell him that we support him and a separate letter to the children [...] So every day they received an email and every afternoon they sent us an answer [...] I asked the children to draw their bedrooms and tell us their favourite bedtime stories. In the evening, we put together all the letters, the drawings and the answers and they had a kind of newspaper where everyone could see the rooms of their peers and know their favourite bedtime stories, with a lot of help from the parents of course. 
On the side of families, beside the lack of suitable technological devices, sometimes parents experienced a feeling of having been abandoned by the school. In the following account, a working-class father recounts his failed attempt to teach the alphabet to his son and his falling back on a strict natural growth education style centred on free play and nutrition.

I tried to teach the alphabet to my son. I realise that you have to look for the right method and to be professional [...] We were really abandoned [...] At one point I gave up with the school. We played a lot with the Avengers, listened to music and saw a lot of things on YouTube. I congratulate myself for the progress we were able to make with him with food [...] He started eating a lot of things he didn't eat before.

(online interview, father of a three-year-old son, Milan, May 2020)

In another excerpt from an online interview in Naples with a working-class housewife and mother, the child's refusal of online lessons was seconded. She defined the activities proposed by teachers as less attractive than television, in this way also showing a mistrust in their competence. Most afternoons, in fact, her four-year-old child was either inside watching cartoons or outside playing ball with cousins or boys from the neighbourhood.

He completely refuses to participate in distance learning activities. The teachers made videos, songs they learned at school; at one point they started with letters but we soon gave up. It was useless! He is a very relational child, he had a hard time thinking that he could only see the teachers above the screen. But then he imagines how captivating the music for children can be on television compared to a teacher who has never even taken a selfie! He got nervous just seeing them. Then in the second phase we started seeing the grandparents again. So, I sent him to the condominium garden that we have next to us. Another family with two children lives there and so they meet outdoors, take a ride on a bike, and above all play with the football [...].

(online interview, mother of a two-year-old son, Naples, June 2020)

By contrast, in middle-class families-described by Lareau as usually enrolling children in numerous age-specific organised activities-the constant presence of children at home dominated family life and created a lot of work, particularly for mothers. The parents view these activities as transmitting important life skills to children. They also stress language use and the development of reasoning. This cultivation approach results in a wider range of experiences for children but also creates a frenetic pace for parents, a cult of individualism within the family, and an emphasis on children's performance (Lareau, 2003).

Of course, this kind of parenting style has faced the demands of distance learning in different ways than the natural growth parental approach. The emphasis on performance and a cultivation based on organised leisure activities and extensive reasoning is evident in the next excerpt. A middle-class mother working as a medical doctor clearly expressed the idea of a time for children marked by organised activities, with a full schedule based on the idea of cultivating talent, before and during distance learning.

I have chosen an English language nursery. For me it is essential that they learn to speak English as well as children in other countries. As an activity when he was very young, I made him do neonatal swimming, then he started doing sports at two-and-a-half years old. He always did basketball and breakdance, but also theatre. Then, suddenly, he was not doing anything because this virus is in progress. So, now at home we made the decanting, painting with hands, the salt dough, the moulds, in short, all those activities at home that the teachers send but then we bought a pre-writing book because, for example, all this part he should have done it in this last year of kindergarten and he didn't. We made him do these exercises, that's it. So, at least he was not left behind.

(online interview, mother of a three-year-old son, Dolianova, March 2020) 
In sum, we have in this section showed some of the ways in which inequalities connected to distance learning have been amplified and re-articulated during the COVID-19 pandemic along the axis of social class. Our analysis suggests that when the walls and boundaries between classrooms and houses fell, the fundamental role of parental involvement was emphasised. However, carrying out assignments from teachers depends on the ability, availability, commitment and competence of parents; evidently with many differences on the basis of the aforementioned different resources, characteristics and connected parenting styles.

\section{FINAL REMARKS}

In this article, we focus on the role of school closures in increasing inequalities for six-year-old and younger children and their families as illustrated by temporal, spatial and social strategies mobilised during the first phase of the pandemic. On the one hand, we explored the issue of when the association between school institutions and children is weakened during a crisis, the mechanisms of social reproduction act more strongly. Therefore, inequalities are both amplified and reshaped along different axes, such as gender, space and social class. On the other hand, thanks to the rich material from online interviews, we highlight that during the crisis, rearrangements and renegotiations of gender roles, new uses of space and education patterns have emerged.

With respect to gender roles, we observed patterns of unfair domestic role redistribution. In the use of space, for example, the crisis has contributed to a reversing of the relative advantages of urban contexts compared to rural contexts. During the pandemic, the rural environment was associated with better living conditions during the confinement. Also, forgotten places (e.g., communal gardens and courtyards) were rediscovered by children and their families, and their uses were collectively reinvented.

Moreover, the relationship between school and family has undergone an evolution that could be a vehicle for change. If elements of conflict persist, their resolution requires insights from both parents and teachers. The collaboration of the family-previously implicit-has, in effect, become an essential element for teachers and their work. When the family has supported the children, distance learning has been successful, and where the family has not been able to do so, distance education has failed.

In addition, the traditional separation between formal and informal education and educational experiences at school and in the family have been temporarily overcome by the pandemic. Our findings describe the momentary reconstitution of a new mixed educational space, where the traditional boundaries were brought together through the mediation of technological devices. The two sides of education, namely, the formal and informal, have been bridged, thereby re-constructing an educational frame that needed the mutual collaboration of teachers and parents allowing an enhanced complicity and comprehension. The experience has also determined a situated learning, which may have improved awareness regarding what is at stake in the family-school relationship. To become part of a shared professional culture, this experience would need to be legitimated through the production and diffusion of an expert educational discourse that can be applied into practices through experimentation and training. Otherwise, professional learning and social capital-built through this very experience-will soon dissipate as the practical needs of everyday schooling tasks take over and restabilise old boundaries.

In fact, in the current condition of emerging normalcy, the final phase of a return to normality (which was not the focus of this contribution) has been realised since the acute health crisis has dissipated. This has subsequently produced a radical inversion of the condition of interaction established in the previous period. The return to school has namely been accomplished within a risk management frame that imposed a rigid separation between what was in and out of school connected by checkpoints. The imperatives of the risk management protocol have imposed a complete prohibition for parents to enter the indoor spaces of the school, thereby exacerbating distances between teachers and parents, and by creating new conditions of stress, control and separation. The space of school and the time of school and family have been radically reduced. Interactions with parents remained mediated by online exchanges, whereas all the activities that traditionally produced a sense of school community with 
the participation of parents (e.g., Christmas celebrations, carnivals and children's public performances) were often cancelled. Furthermore, the fear of COVID-19 has created greater diffidence and conflict in local communities as anyone can be suspected of being a vector for the virus, or to not respect the protocols.

In conclusion, it is up to the researchers to transmit and witness the exceptionality of an experience that had a substantial impact on educational practices. Continued research and teaching based on what has been learned from the confinement period can be very useful for practitioners and policymakers in the future.

\section{DATA AVAILABILITY STATEMENT}

The data that support the findings of this study are available from the author upon reasonable request.

\section{ENDNOTES}

${ }^{1}$ From September 2020 to the end of February 2021, kindergarten children in Bari, for example, were able to attend 48 days out of the 107 planned in person, compared with their peers in Milan, who were on the calendar for 112 days. Middle school students in Naples attended 42 days out of 97, while those in Rome attended the entire period in person. As for the boys and girls of the high schools of Reggio Calabria, they were able to attend in-person classes for 35.5 days out of 97 scheduled, while peers in Florence went to school 75.1 days out of 106 (Save the Children, 2021).

2 According to ISTAT (2018), 41.9\% of children live in overcrowded homes and do not have a quiet space available to connect online and study. A decidedly lower but significant share, equal to $7 \%$ of children (and $7.9 \%$ of $18-24$ years olds) live in conditions of severe housing deprivation (structural problems, without a bath/shower with running water, with problematic lighting).

3 Rasmussen highlights that 'places for children' are not always the 'places of children', meaning the informal ones they choose for themselves and which they appropriate independently, thus revealing their own spatial culture (Rasmussen, 2004).

\section{REFERENCES}

Ball, S. (2009). Lifelong learning, subjectivity, and the totally pedagogised society. In M. A. Peters, A. C. Besley, M. Olssen, S. Maurer \& S. Weber (Eds.), Govermentality studies in education (pp. 201-216). Sense Publishers.

Bernstein, B. (2000). From pedagogies to knowledges. In A. Morais, I. Neves, B. Davies, \& H. Daniels (Eds.), Towards a sociology of pedagogy: The contribution of Basil Bernstein to research (pp. 363-368). Peter Lang.

Bourdieu, P. (1994). Raisons pratiques. Sur la théorie de l'action. Seuil.

Bourdieu, P. (1998). La domination masculine. Seuil.

Cohen, S. (1972). Folk devils and moral panics: The creation of the Mods and Rockers. Martin Robertson.

Corsaro, W. A. (2017). The sociology of childhood. Indiana University.

England, P. (2010). The gender revolution: Uneven and stalled. Gender \& Society, 24(2), 149-166. https://doi. org/10.1177/0891243210361475

Ennew, J. (1994). Time for children or time for adults? In J. Qvortrup, M. Bardy, G. Sgritta \& H. Wintersberger (Eds.), Childhood matters. Social theory, practice and politics (pp. 125-143). Aldershoot.

Glaser, B. G., \& Strauss, A. L. (1967). The discovery of grounded theory: Strategies for qualitative research. Aldine.

Hochschild, A. (2013). So how's the family? And other essays. University of California Press.

ISTAT. (2011). La conciliazione tra lavoro e famiglia. Statistical report, 28-12-2011.

ISTAT. (2018). Condizioni economiche delle famiglie. Website: https://www.istat.it/it/condizioni-economiche-famiglie?dati James, A., Jenks, C., \& Prout, A. (2002). Teorizzare l'infanzia. Per una nuova sociologia dei bambini. Donzelli.

Kaufmann, J. C. (1995). Trame coniugali: Panni sporchi e vita di coppia. Edizioni Dedalo.

Knoblauch, H., \& Löw, M. (2017). On the spatial re-figuration of the social world. Sociologica, 7(2), 1-27.

Kuhn, T. S. (1970). The structure of scientific revolutions. University of Chicago Press.

Lareau, A. (2000). Home advantage: Social class and parental intervention in elementary education. Rowman \& Littlefield Publishers.

Lareau, A. (2003). Unequal childhoods: Class, race, and family life. University of California Press.

Naldini, M. (Ed.). (2015). La transizione della genitorialità. II Mulino.

Rasmussen, K. (2004). Places for children-Children's places. Childhood, 11(2), 156-173. https://doi.org/10.1177/09075 68204043053 
Robertson, S. L., \& Sorensen, T. (2018). Global transformations of the state, governance and teachers' labour: Putting Bernstein's conceptual grammar to work. European Educational Research Journal, 17(4), 470-488. https://doi. org/10.1177/1474904117724573

Santagati, M., \& Barabanti, P. (2020). (Dis)connessi? Alunni, genitori e insegnanti di fronte all'emergenza Covid-19. Media Education, 11(2), 109-125. https://doi.org/10.36253/me-9646

Satta, C. (2010). Qui dentro non è come là fuori. Surrogati di domesticità in uno spazio gioco per l'infanzia. In V. Belotti \& S. la Mendola (Eds.), Il futuro nel presente. Per una sociologia delle bambine e dei bambini (pp. 197-226). Guerini Scientifica.

Satta, C. (2012). Bambini e adulti. La nuova sociologia dell'infanzia. Carocci.

Save the Children. (2021). Childhood in the time of Covid. Complement to the Global Children Report. https://www.savet hechildren.org/content/dam/usa/reports/advocacy/2021-us-childhood-report.pdf

Singh, P. (2015). Performativity and pedagogising knowledge: Globalising educational policy formation, dissemination and enactment. Journal of Education Policy, 30(3), 363-384. https://doi.org/10.1080/02680939.2014.961968

How to cite this article: Pitzalis, M., \& Spanò, E. (2021). Stay home and be unfair: The amplification of inequalities among families with young children during COVID-19. European Journal of Education, 00, 1-12.

https://doi.org/10.1111/ejed.12481 